Discussion Paper No. 04-42

Regional Income Convergence in the Enlarged Europe, 1995-2000: A Spatial Econometric Perspective

Manfred M. Fischer and Claudia Stirböck

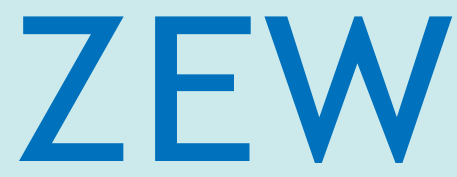

Zentrum für Europäische Wirtschaftsforschung $\mathrm{GmbH}$ Centre for European Economic Research 
Discussion Paper No. 04-42

\title{
Regional Income Convergence in the Enlarged Europe, 1995-2000: A Spatial Econometric Perspective
}

\author{
Manfred M. Fischer and Claudia Stirböck
}

Download this ZEW Discussion Paper from our ftp server:

\author{
ftp://ftp.zew.de/pub/zew-docs/dp/dp0442.pdf
}

Die Discussion Papers dienen einer möglichst schnellen Verbreitung von neueren Forschungsarbeiten des ZEW. Die Beiträge liegen in alleiniger Verantwortung der Autoren und stellen nicht notwendigerweise die Meinung des ZEW dar.

Discussion Papers are intended to make results of ZEW research promptly available to other economists in order to encourage discussion and suggestions for revisions. The authors are solely responsible for the contents which do not necessarily represent the opinion of the ZEW. 


\section{Non-technical Summary}

Questions of convergence have received increasing attention in recent years, in light of the pressure for greater integration and enlargement of the European Union [EU] to countries in Central and Eastern Europe [CEE]. This paper looks at the evidence for convergence of per capita income between regions in Europe in the second half of the 1990s, when economic recovery in CEE gathered pace.

The analysis starts with the simplest of the models, the unconditional $\beta$-convergence model. $\beta$-convergence measures the correlation between per capita output levels and growth rates of cross-sections of regions. A negative correlation is taken as evidence of convergence. The analysis of this paper shows that the classical test methodology is ill-designed due to two reasons. First, it cannot identify groupings of regional economies that are converging. Second, it neglects spatial effects that represent interregional interactions and spatial spillovers.

The paper suggests a much richer and theoretically more satisfactory approach that is in line with both the notions of club convergence and spatial dependence, and reflects recent developments in spatial econometrics. The two-club spatial error convergence model with club-wise heteroskedasticity appears to be the most appropriate specification in view of the data available.

In the paper, we find clear evidence for unconditional $\beta$-convergence in Europe for the time period of observation. The sample of regional economies belonging to club $A$ converges in an unconditional sense at a speed of 1.5 percent per year and those belonging to club $B$ (regional economies in CEE and Southern Europe) at a speed of 2.4 percent. It is important to emphasise that a speed of 1.5 or 2.4 percent per year, even though in accordance with previous findings of convergence studies, is very small. However, we identify a higher convergence speed for regions in Central and Eastern Europe, thus indicating a process of catching-up towards the richer Western regions.

The study also illustrates that the classical convergence test methodology that has been the work-horse of most previous convergence studies in mainstream economics is ill-designed to analyse regional convergence due to the existence of spatial autocorrelation. Ignoring the presence of spatial error autocorrelation in convergence analysis carried out with crosssectional data can lead to wrong conclusions, for example, with respect to the assessment of convergence speed. Thus, testing for the presence of spatial autocorrelation (heterogeneity) by means of appropriate diagnostics and implementing alternative specifications of the convergence test equation when needed are crucial issues in income convergence analysis. 


\title{
Regional Income Convergence in the Enlarged Europe, 1995-2000: A Spatial Econometric Perspective
}

\author{
Manfred M. Fischer \\ (Vienna University of Economics and Business Administration) \\ and \\ Claudia Stirböck \\ (Centre for European Economic Research/ZEW, Mannheim)
}

June 2004

\begin{abstract}
This paper adopts a spatial econometric perspective to analyse regional convergence of per capita income in Europe in 1995 to 2000 and, moreover, relaxes the assumption of a single steady-state growth path which appears to be out of tune with reality of empirical dynamics. The two-club spatial error convergence model with groupwise heteroskedasticity is found to be most appropriate for the data at hand. Two empirical key findings are worthwhile to note. The first is that the data provide much support for unconditional $\beta$-convergence in Europe. The second is that the usual convergence conclusions hold. But they do so for reasons that are not revealed by the classical test equation that is typical in mainstream economics literature.
\end{abstract}

\section{Acknowledgments}

The authors are grateful to Thomas Scherngell, Katharina Kobesova and Heiko Truppel for valuable research assistance. We also thank participants at the EEFS 2004 and the NOeG 2004 conferences for helpful comments. All remaining errors, however, are our own.

JEL Classification: C21, O52, R11, R15

Keywords: European Regions, Income Convergence, Spatial Econometrics

Manfred M. Fischer

Vienna University of Economics

and Business Administration

Roßauer Lände 23/1

A-1090 Wien

Tel.: +43 1 31336-4808

Fax: +43-1-31336-703

Email: manfred.fischer@wu-wien.ac.at

\author{
Claudia Stirboeck \\ ZEW (Centre for European \\ Economic Research) \\ P.O. Box 103443 \\ D-68034 Mannheim \\ Tel.: +49-621-1235-218 \\ Fax: +49-621-1235-223 \\ E-Mail: stirboeck@zew.de
}




\section{Introduction}

At the beginning of the century, questions of convergence have become a matter of increasing concern for policy makers in Europe, not only within the EU-15, but also in the accession countries in Central and Eastern Europe. Measuring the extent to which convergence exists is far from straightforward due to several reasons. First, there are measurement problems. In particular, there is a lack of reliable gross regional product [GRP] figures for CEE regions. This comes partly from the change in accounting conventions now used in CEE economies. More important, even if reliable estimates of the change in the volume of output produced did exist, it would be impossible to interpret them meaningfully because of the fundamental change of production, from a centrally planned to a market economy system. As a consequence, figures for GRP are difficult to compare between CEE and EU regions until the mid 1990s (European Commission, 1999).

Second, there does not exist a consensus methodological framework to guide empirical work on testing for regional convergence. Instead, several distinct types of convergence have been suggested in the literature, each implying different test equations. Broadly considered, empirical tests fall into three categories. The first and dominating type of test studies analyses the cross-section correlation between per capita output levels and subsequent growth rates for countries or regions. A negative correlation is taken as evidence of convergence as it implies that - on average - economies with low per capita initial incomes are growing faster than those with higher initial per capita incomes. This form of convergence has been termed $\beta$-convergence.

The second type of test studies investigates whether the cross-section variance of per capita output levels tends to decrease over time. This form of convergence has been called $\sigma$-convergence. It is important to recognise that the existence of $\beta$-convergence is a necessary, but not sufficient condition for $\sigma$-convergence (see Bernard and Durlauf, 1996; Quah, 1996). The third type of tests focuses attention on the long-run behaviour of differences in per capita output across economies. These tests interpret convergence to mean that these differences are transitory in the sense that long-run forecasts of the difference between any pair of economies converge to zero as the forecast horizon grows. Convergence in this sense is called time series forecast convergence (Bernard and Durlauf, 1996).

Contemporary expectations of catch-up in Europe largely rest on the implicit acceptance of models of $\beta$-convergence. This motivates to analyse whether regional economies exhibit $\beta$-convergence and if so to estimate the time needed to attain equilibrium. The study considers the behaviour of output differences across 256 regions embracing all the EU-15 countries and the CEE accession countries ${ }^{1}$. The study refers to the time interval

\footnotetext{
${ }^{1}$ Bulgaria, Czech Republic, Estonia, Hungary, Latvia, Lithuania, Poland, Romania, Slovakia and Slovenia. Malta and Cyprus are excluded from the analysis due to their isolated location.
} 
1995-2000 and equates convergence with the tendency to narrow. Output is measured in terms of per capita GRP. While the study shares ideas with much convergence analysis in mainstream economics ${ }^{2}$, it differs from most studies in two major aspects. First, it adopts a spatial econometric perspective to allow for spatial interactions and spillovers between regions as mechanisms that may lead to convergence. Second, it relaxes the implicit assumption of a single steady-state growth path which seems out of tune with the reality of empirical dynamics [see Quah (1993)]. Instead the study allows groupings of regional economies [so-called convergence clubs in the sense of Baumol (1986)] to form so that regional economies within a group interact more with each other than with those outside.

The rest of the paper is structured as follows. It is natural to start in Section 2 with a definition of the notion of convergence and a brief outline of the test methodology for classical cross-section $\beta$-convergence analysis. We call the methodology classical because it was the first in the literature, uses conventional techniques of classical econometrics only and is widely spread in mainstream economics. Regions are considered as isolated entities, as if their geographical location and potential in the regional linkages would not matter. Section 3 extends the classical test methodology to escape the criticism of assuming independently distributed observational units and to more fully treating spatial effects in convergence processes. Section 4 continues to describe the data and the empirical procedure suggested for identifying clubs of regional economies from a spatial econometric perspective. Section 5 presents the estimation results of the spatial econometric models in comparison to those of the classical models of unconditional $\beta$-convergence. We conclude the paper with a brief summary and some further thoughts.

\section{Convergence and Cross-Section Tests}

The cross-section approach to convergence analysis considers the behaviour of the output differences between regional economies over a fixed time interval and equates convergence with the tendency of the difference to narrow. Following Bernard and Durlauf (1996) we say regional economies $j$ and $j$ converge over the time period $(t, t+\tau)$ if the (log) per capita output disparity at $t$ is expected to decrease in value.

Let $y_{j t}$ denote the log-normal per capita gross-regional product [GRP] of region $j$ at $t$ and $\mathfrak{F}_{t}$ all information available at this time then convergence between a pair of regional economies $\left(j, j^{\prime}\right)$ can be defined as follows: If $y_{j t}>y_{j^{\prime} t}$ then

$$
E\left[y_{j t+\tau}-y_{j^{\prime} t+\tau} \mid \mathfrak{F}_{t}\right]<y_{j t}-y_{j^{\prime} t} .
$$

\footnotetext{
${ }^{2}$ Recent surveys of the literature can be found in Durlauf and Quah (1999), Temple (1999) and Fingleton (2003).
} 
This definition can easily be extended to convergence between a set of $N$ regional economies by requiring that every pair $\left(j, j^{\prime}\right)$ within the set exhibits convergence. It is worthwhile to note that in the context of the current paper the conditional expectation is taken with respect to the linear space generated by current and lagged regional income differences rather than in a general $\mathfrak{F}_{t}$ sense. Therefore the definition is equivalent to require that $y_{j t}-y_{j^{\prime} t}$ is a linearly regular process.

Classical convergence tests, used by Baumol (1986), Barro (1991), Barro and Sala-iMartin (1991, 1992) and many others, investigate on the basis of the above definition how an economy's average income growth co-moves with initial income. Defining the average growth rate

$g_{j \tau}=\frac{1}{\tau}\left(y_{j t+\tau}-y_{j t}\right)$

for a set of $N$ regional economies then the basic test used has the following form ${ }^{3}$

$g_{j \tau}=\alpha+\beta y_{j t}+\varepsilon_{j \tau}$

for $j=1, \ldots, N$, where $\tau$ is a fixed time horizon and $E\left[\varepsilon_{j \tau} \mid \mathfrak{F}_{t}\right]=0, y$ is the variable [lognormal per capita GRP] being tested for convergence, $\varepsilon$ a white noise error term, and $\alpha$ and $\beta$ parameters to be estimated. Empirical work using Equation (3) as testing framework has equated convergence with a negative estimate of $\beta$, treating $\beta \geq 0$ as the no convergence null hypothesis.

By drawing on reasoning given by Bernard and Durlauf (1996) the requirement may be written as a constraint on the mean of output differences between two time series. Observing that

$g_{j \tau}=\frac{1}{\tau} \sum_{t=1}^{\tau} \Delta y_{j t}$

where $\Delta y_{j t}=y_{j t+1}-y_{j t}$ then Equation (3) implies that

\footnotetext{
${ }^{3}$ In some formulations of cross-section convergence tests, Equation (3) is modified to include a set of variables allowing for differences in steady-states and asymmetric shocks [see, just to cite a few examples, Barro and Sala-iMartin (1991), (1992) and (1995), Sala-i-Martin (1996)]: $g_{j \tau}=\alpha+\beta y_{j t}+\Pi \boldsymbol{x}_{j t}+\varepsilon_{j \tau}$, where $\boldsymbol{x}_{j t}$ is a vector of variables that influences the steady-state level of regional economy $j$. A negative $\beta$ means then that convergence holds conditional on a set of exogenous variables such as savings and population growth for region $j$ (conditional $\beta$ convergence). While potentially important in practice, for the discussion in this paper the differences between conditional and unconditional convergence do add neither conceptual insights nor difficulties in modelling the spatial dimension of the convergence process. Thus, we will not consider conditional convergence further in this paper.
} 


$$
\frac{1}{\tau} \sum_{t=1}^{\tau} \Delta y_{j t}-\frac{1}{\tau} \sum_{t=1}^{\tau} \Delta y_{j^{\prime} t}=\beta\left(y_{j t}-y_{j^{\prime} t}\right)+\varepsilon_{j t}-\varepsilon_{j^{\prime} t}
$$

If $y_{j t}-y_{j^{\prime} t}$ is positive, then the requirement that $\beta$ is negative implies that the expected value of the left hand side of Equation (5) is negative. From the perspective of bivariate comparisons, the cross-section $\beta$-test, thus, analyses whether the average change in per capita GRP of an initially poorer region exceeds that of an initially richer one (Bernard and Durlauf, 1996). Recall that the ordinary least squares estimator $\beta$ can be written as

$$
\hat{\beta}=\sum_{j=1}^{N} \varphi_{j} \theta_{j}
$$

where

$$
\begin{aligned}
& \varphi_{j}=\left(y_{j t}-\overline{y_{j t}}\right)^{2} / \sum_{j=1}^{N}\left(y_{j t}-\overline{y_{j t}}\right)^{2} \\
& \theta_{j}=\left(g_{j \tau}-\overline{g_{j \tau}}\right) /\left(y_{j t}-\overline{y_{j t}}\right)
\end{aligned}
$$

with

$$
\begin{aligned}
& \overline{y_{j t}}=\frac{1}{N} \sum_{j=1}^{N} y_{j t} \\
& \overline{g_{j \tau}}=\frac{1}{N} \sum_{j=1}^{N} g_{j \tau}
\end{aligned}
$$

then it is evident that $\beta$ equals a weighted average of the ratio of differences of growth rates from the sample means to differences of initial incomes from the sample mean. Thus, cross-section tests require that a weighted average of regional economies with above average initial incomes grow at a slower rate than the mean growth of the crosssection. In equating convergence with the neoclassical growth model, the testable restriction of the model as analysed in cross-section tests implies that the first moments of the stochastic processes governing growth rates differ for initially rich and poor economies (Bernard and Durlauf, 1996).

Suppose that the estimate of $\beta$ is negative. Since $\beta$ is a weighted average of $\theta_{j}$ 's [see Equations (6)-(10)], a negative estimate means that the output differences between some 
pairs of regional economies have declined over the sample. Thus, for $\mathfrak{F}_{t}$ consisting exclusively of a constant, some pairs of regions are converging in the sense of the above convergence definition. But, the cross-section test defined by Equation (3) cannot identify groupings of regions that are converging.

In equating convergence with the neoclassical growth model ${ }^{4}$ with its diminishing returns to capital convergence mechanism [see Barro and Sala-i-Martin (1992), Mankiw, Romer and Weil (1992) among others], the constant term, $\alpha$, in Equation (3) can be interpreted as an equilibrium rate of income growth, and $\beta$ is related to the rate of convergence $\left(\right.$ say, $\beta^{*}$ ) to a region's steady-state, a measure of how fast regions attain their long-run equilibrium path:

$\beta=-\frac{1}{\tau}\left[1-\exp \left(-\beta^{*} \tau\right)\right]$

Estimating Equation (3) jointly with Equation (11) constitutes the canonical ß-convergence analysis in a neoclassical world ${ }^{5}$.

The existence of the equilibrium in a neoclassical world is due to the assumption that there are diminishing returns to capital determined by the capital share coefficient in the Cobb-Douglas production function. Whether or not convergence happens is a matter of assumptions on the form of the production function and not of interactions across economies (Durlauf and Quah, 1999). Canonical $ß$-convergence analysis does not take into account other equilibrating mechanisms such as capital flows, labour migration or technological spillovers across regional economies. Regions are treated as 'isolated islands' [Quah (1993), Martin (2001), Rey (2001) among others].

\section{A Spatial Econometric Approach to Convergence Analysis}

A key limitation of the majority of empirical analyses of cross-sectional regional growth has been that the assumption of a single steady-state has to hold for all regional economies in the sample (Durlauf, 2001). If regional economies, for example, differ in their basic growth parameters (such as technological innovativeness, human capital

\footnotetext{
${ }^{4}$ Barro and Sala-i-Martin (1992) have shown that the growth regression Equation (3) may be derived - as a loglinear approximation - from the transition path of the neoclassical growth model for closed economics. Many studies of convergence empirics share this neoclassical underpinning. The assumption of diminishing returns that drives the neoclassical convergence process is one that is particularly questionable for regional economies. But there are solid empirical reasons why it makes sense to fit growth regression models in which there is a significant convergence process even if the reasons for this convergence may be debated.

${ }^{5}$ Instead of estimating Equation (3) and using Equation (11) to compute the speed, $\beta^{*}$, one can estimate a non-linear least squares [NLS] relation directly.
} 
development, etc.), or knowledge spillovers between them are weak, they may not converge to a common per capita income, but instead to different economic-specific equilibrium levels of per capita income. Different regional economies may be converging to different long-run growth rates, just because of different initial conditions. Under such circumstances there might be convergence among similar types of economies (club convergence), but little or no convergence between such clubs (Martin, 2001).

This motivates to adopt a framework that enables testing for club convergence. We allow 'natural groupings' of regional economies to form, in the sense that regional economies within a group interact more with each other than with those outside. Club identification in this study is performed with the help of exploratory spatial data analysis [ESDA] focusing on the explanatory variable that defines the initial conditions of the convergence process. This technique is a convenient way of detecting spatial regimes in the data (for more details see Section 4). The virtue of the procedure lies in its ability to uncover spatial effects and spillovers among regional economies on the basis of initial incomes.

The discussion that follows will be easier to understand if one keeps in mind that the basic test equation, the classical (unconditional) convergence model, can be reformulated in matrix form as

$\boldsymbol{g}=\boldsymbol{Y} \gamma+\varepsilon$

where $\boldsymbol{g}$ is a $(N, 1)$-vector of observations on the dependent variable [average lognormal of per capita GRP growth rates] for the $N$ regions. The $(2,1)$-vector $\gamma$ consists of two components: $\alpha$ and $\beta$ in the notation of Equation (3). The second component is the coefficient of the explanatory variable: log-normal of initial per capita GRP. The coefficient $\alpha$ is a constant term and can be interpreted as the coefficient of an exogenous (explanatory) variable which takes the unit value for each of the $N$ observations. Thus, $\boldsymbol{Y}$ is a $(N, 2)$-matrix of observations on the two exogenous variables. $\varepsilon$ is a $(N, 1)$-vector of random disturbance terms. For the data-generating process it is assumed that the elements of the random vector $\varepsilon$ are identically and independently distributed (i.i.d.). Thus, the error variance-covariance matrix is $E\left[\begin{array}{ll}\varepsilon & \varepsilon^{\prime}\end{array}\right]=\sigma^{2} I_{N}$, where the scalar is $\sigma^{2}$ unknown, $I_{N}$ a Nth-order identity matrix and $\varepsilon$ denotes the transpose of $\varepsilon$. The parameter $\gamma$ can be estimated by means of ordinary least squares [OLS].

It is straightforward to adopt this standard cross-section growth regression framework to account for club convergence. For matter of representation let us consider two clubs only, indicated by the indices $A$ and $B$. These clubs correspond to subsets of the observations for which the regression model follows a different set of coefficients. Each club may be represented by a different cross-sectional equation. Then the two-club growth regression model can formally be expressed as 
$\left[\begin{array}{l}\boldsymbol{g}_{A} \\ \boldsymbol{g}_{B}\end{array}\right]=\left[\begin{array}{cc}\boldsymbol{Y}_{A} & 0 \\ 0 & \boldsymbol{Y}_{B}\end{array}\right]\left[\begin{array}{l}\gamma_{A} \\ \gamma_{B}\end{array}\right]+\left[\begin{array}{l}\boldsymbol{\varepsilon}_{A} \\ \boldsymbol{\varepsilon}_{B}\end{array}\right]$

where $\boldsymbol{g}_{A}$ and $\boldsymbol{g}_{B}$ are the dependent variables; $\boldsymbol{Y}_{A}$ and $\boldsymbol{Y}_{B}$ the explanatory variables; $\gamma_{A}$ and $\gamma_{B}$ the coefficients; and $\varepsilon_{A}$ and $\varepsilon_{B}$ the errors in the respective clubs $A$ and $B$ of regions. Let $N_{A}$ and $N_{B}$ denote the number of observations in club $A$ and club $B$, respectively. Then $N=N_{A}+N_{B}$.

The simple block structure of the two-club model (13) can be expressed more succinctly in one equation

$$
\boldsymbol{g}^{*}=\boldsymbol{Y}^{*} \gamma^{*}+\boldsymbol{\varepsilon}^{*}
$$

where the boldface variables without subscript refer to combined variable, coefficient and error matrices.

Since the full set of elements of the error variance matrix $\Psi=E\left[\varepsilon^{*} \varepsilon^{*}\right]$ is generally unknown and cannot be estimated from the data due to a lack of degrees of freedom, it is necessary to impose a simplifying structure. The most straightforward assumption is a model with a constant error variance over the whole set of observations:

$\boldsymbol{\Psi}=\sigma^{2} \boldsymbol{I}_{N}$

where $\sigma^{2}$ is the constant error variance. This specification leads to the so-called classical two-club convergence model that conforms to the standard assumptions of the classical test methodology.

But this assumption may be overly restrictive. Assuming an error variance that is different in each of the clubs of regions results in a special form of heteroskedasticity

$\boldsymbol{\Psi}=\left[\begin{array}{cc}\sigma_{A}^{2} \boldsymbol{I}_{A} & 0 \\ 0 & \sigma_{B}^{2} \boldsymbol{I}_{B}\end{array}\right]$

where $\sigma_{A}^{2}$ and $\sigma_{B}^{2}$ denote the club-specific constant error variances, $\boldsymbol{I}_{A}$ and $\boldsymbol{I}_{B}$ are identity matrices of dimensions $N_{A}$ and $N_{B}$. This specification results into the two-club growth regression model with groupwise heteroskedasticity. Estimation and testing can be carried out by means of fairly straightforward iterative techniques [so-called estimated GLS] or in a maximum likelihood framework (Anselin, 1990). 
In both cases, the homoskedastic version and the heteroskedastic version of the two-club convergence model, spatial error dependence ${ }^{6}$ is likely to be a problem. It can arise due to several reasons. First, if there is a lack of independence between the observational units. Second, spatial error dependence may reflect important aspects of phenomena such as capital flows, labour migration or technological spillovers in the regional growth process. Third, spatial dependence can also arise from a variety of measurement problems, such as boundary mismatching between the administrative boundaries used to organise the data series and the actual boundaries of the economic processes believed to generate regional convergence or divergence. Finally, it should be noted that any parsimonious regression model, in particular the club-specific version of the canonical equation of $\beta$-convergence leaves out many factors that would - from the perspective of economic theory - be likely to affect the parameter of the initial income. When there are omitted variables that are spatially autocorrelated, regression analysis will produce spatially dependent residuals, given that the omitted variables are relevant and the dependent variable is itself spatially autocorrelated.

When spatial dependence is present in the error term, the above two-club convergence models are misspecified. Spatial autocorrelation may be modelled by specifying a spatial process for the disturbance terms $\varepsilon^{*}$. Different spatial processes lead to different error covariances, with varying implications about the range and extent of spatial interaction and spillovers in the model. The most common specification is a spatial autoregressive [SAR] process in the error terms $\varepsilon^{*}$ :

$$
\varepsilon^{*}=\rho W \varepsilon^{*}+\mu
$$

where $\boldsymbol{W}$ is the spatial weights matrix ${ }^{7}$ of dimension $N$ by $N, \rho$ is a scalar spatial autoregressive coefficient for the spatial error lag $\boldsymbol{W \varepsilon ^ { * }}$, and $\mu$ is a vector of i.i.d errors with variance $\sigma_{\mu}^{2}$. The combination of Equation (14) and Equation (17) makes up the two-club spatial error convergence model. The resulting error covariance will be nonspherical. Thus, ordinary least squares estimation of this model would yield unbiased estimates for the convergence parameter $\beta$, but to a biased estimation of the residual variance and inefficient estimates of the regression coefficients as well as unreliable standard regression diagnostics (Anselin and Rey, 1991). Therefore, inferences about the convergence process have to be based on the model estimated via maximum likelihood [ML] or general methods of moments [GMM].

\footnotetext{
${ }^{6}$ Cross-regional data are spatial data. Spatial data are characterized by dependence [spatial autocorrelation] and heterogeneity [spatial heterogeneity] (Anselin, 1988). Spatial error dependence is the situation where the error term at each region is correlated with values for the error term at other regions. We use the terms spatial dependence and spatial autocorrelation interchangeable in this paper.

${ }^{7}$ The spatial weights matrix consists of positive elements for pairs of locations $(i, j)$, with $w_{i j} \neq 0$ for 'neighbours' and $w_{i j}=0$ for others. By convention, the diagonal elements $w_{i i}$ are set to zero. For an extensive discussion see Anselin (1988). In practice, the derivation of spatial weights from the location and spatial arrangements of observation is carried out by means of a geographic information system.
} 
As is well-known in spatial econometrics Equation (17) can be rewritten as

$\varepsilon^{*}=A^{-1} \mu$

with

$\boldsymbol{A}=\left(\boldsymbol{I}_{N}-\rho \boldsymbol{W}\right)$.

Depending on the structure of the error variance in club $A$ and club $B$, two model forms of two-club growth regression may be distinguished. In the first, the homoskedastic error case:

$E\left[\mu \mu^{\prime}\right]=\sigma_{\mu}^{2} \boldsymbol{I}_{N}$

and the overall variance-covariance matrix takes the form

$\boldsymbol{\Psi}=\sigma_{\mu}^{2}\left(\boldsymbol{A}^{\prime} \boldsymbol{A}\right)^{-1}$

If the spatial structure is not constant across the geography, heteroskedasticity may result, even though the initial process (17) is not heteroskedastic. In this case, the heteroskedastic error case, it is reasonable to assume that the two clubs have different error variances $\left(\operatorname{var}\left[\mu_{A}\right]=\sigma_{\mu_{A}}^{2} \neq \sigma_{\mu_{B}}^{2}=\operatorname{var}\left[\mu_{B}\right]\right)$. Then the covariance matrix for the $\mu$ terms becomes

$$
E\left[\begin{array}{ll}
\mu & \mu^{\prime}
\end{array}\right]=\boldsymbol{\Omega}=\left[\begin{array}{cc}
\sigma_{\mu_{A}}^{2} \boldsymbol{I}_{A} & 0 \\
0 & \sigma_{\mu_{B}}^{2} \boldsymbol{I}_{B}
\end{array}\right]
$$

\section{Data, Spatial Weights Matrix and Spatial Clubs}

The data on per capita $\mathrm{GRP}^{8}$ used in this study are cross-section data in logarithmic form. They are based on the European System of Accounts. The growth rate is observed as an average over 1995 to 2000 rather than at a point of time. We focus on NUTS-2

\footnotetext{
${ }^{8}$ The use of real GRP data would be preferable due to the large price differentials across the EU. However, no data on regional price levels is available so far.
} 
regions ${ }^{9}$ which are formal (that is, administrative or political) rather than functional spatial units and represent the boundaries of economic processes believed to generate regional convergence or divergence.

Our sample includes 256 NUTS-2 regions across 25 countries in Europe:

- The member states of the European Union: Austria [9 regions], Belgium [11 regions], Denmark [1 region], Finland [6 regions], France [22 regions], Germany [40 regions], Greece [13 regions], Ireland [2 regions], Italy [20 regions], Luxembourg [1 region], the Netherlands [12 regions], Portugal [5 regions], Spain [16 regions], Sweden [8 regions], and UK [37 regions]; and

- the accession countries in CEE: Bulgaria [6 regions], the Czech Republic [8 regions], Estonia [1 region], Hungary [7 regions], Latvia [1 region], Lithuania [1 region], Poland [16 regions], Romania [8 regions], the Slovak Republic [4 regions], and Slovenia [1 region].

\section{Spatial Weights Matrix}

A spatial weights matrix is a $N$ by $N$ positive and symmetric matrix $\boldsymbol{W}$ which expresses for each observation (row) those regions (columns) that belong to its neighbourhood set as non-zero elements. The specification of which elements are non-zero is a matter of considerable arbitrariness. We use the traditional approach that is based on the geography of the observations, designating regions as 'neighbours' when they are within a given distance of each other, i.e. $w_{i j}=1$ for $d_{i j} \leq \delta$ and $i \neq j$, where $d_{i j}$ is the great circle distance between the capital cities of region $i$ and $j$, and $\delta$ is a distance cut-off value [distance-based contiguity]. The spatial weights matrix $W^{*}$ is, thus, defined by the following equation

$$
w_{i j}^{*}=\left\{\begin{array}{l}
0 \text { if } i=j \\
1 \text { if } d_{i j} \leq \delta \text { for } i \neq j \\
0 \text { if } d_{i j}>\delta \text { for } i \neq j .
\end{array}\right.
$$

For ease of interpretation, the matrix is standardized so that the elements of a row sum to one. Therefore, the elements of the row-standardized spatial weights matrix $\boldsymbol{W}$ equal to

$$
w_{i j}=\frac{w_{i j}^{*}}{\sum_{j=1}^{N} w_{i j}^{*}} \quad i, j=1, \ldots, N
$$

\footnotetext{
${ }^{9}$ The European Commission uses NUTS regions as targets for the convergence process and has defined NUTS-2 as the spatial level at which to measure convergence or divergence.
} 
This ensures that all weights are zero or one. $\delta$, the critical cut-off value ${ }^{10}$, is chosen as $350 \mathrm{~km}$ on the basis of exploratory analysis and theoretical considerations.

\section{Spatial Clubs}

Economic theory does not provide guidance as to either the number of clubs or the way in which the explanatory variable defining the initial conditions determines clubs (Durlauf and Johnson 1995). Thus, it is reasonable to allow patterns of cross-section interaction - clustering together in convergence clubs - to endogenously emerge. A convergence club is a group of regional economies that interact more with each other than with those outside and that exhibit initial conditions which are near enough to converge towards the same long-run equilibrium. We use the Getis-Ord statistic $G_{i t}^{*}$, a measure of spatial clustering, to determine clubs of regions on the basis of spatial association in per capita GRP 1995 where spatial association reflects spatial externalities among regions $j$ within a distance $\delta$ of region $i$. The statistic allows to identify spatial regimes in the data by use of the concept called proximal space (Getis and Ord 1992, Ord and Getis 1995) and is formally defined as

$G_{i t}^{*}(\delta)=\frac{\sum_{j=i}^{N} w_{i j}(\delta) y_{j t}}{\sum_{j=1}^{N} y_{j t}}$

where $w_{i j}(\delta)$ are the elements of a spatial weights matrix as defined in (23)-(24), with ones for all links defined as being within distance $\delta$ of a region $i$, all other links are zero. The numerator is the sum of all $y_{j t}(t=1995)$ within $\delta$ of $i$.

Any pattern of spatial association identified in terms of the computed $Z\left[G_{i t}^{*}(\delta)\right]$-values can be interpreted as spatial concentration of high or low values of GRP. A positive [significant] $Z\left[G_{i t}^{*}(\delta)\right]$-value indicates a spatial cluster of high values, whereas a negative one indicates a cluster of low values. The information obtained from this statistic for all $i=1, \ldots, N$ is taken to determine two spatial clubs according to the following simple rule: If $Z\left[G_{i t}^{*}(\delta)\right]$ is positive, region $i$ is allocated to spatial club $A$; and if $Z\left[G_{i t}^{*}(\delta)\right]$ is negative, region $i$ becomes a member of spatial club $B^{11}$. The result of this procedure outlined in Figure 1 seems - overall considered - quite reasonable. Richer regions tend to be clustered in club $A$ and poorer regions in club $B$.

\footnotetext{
${ }^{10}$ This means that above the critical value of $350 \mathrm{~km}$ spatial interactions are assumed to be negligible.

${ }^{11}$ Spatial club $A$ (club $B$ ) represents a strong pattern which suggests that around region $i$ regions with high (low) GRP tend to be clustered more often than would be due to random choice.
} 
Spatial club A consists of 173 regions and includes all the EU-15 regions except those in Greece and Portugal, some Spanish regions [Galicia, Extremadura, Andalucia], some Southern Italian regions [Calabria, Apulia and Sicilia], regions located in Eastern Austria [Upper Austria, Lower Austria, Vienna, Burgenland, Styria], as well as Dresden and Berlin; plus two regions located in CEE [Slovenia and the most Western region in the Czech Republic].

Spatial club B [83 regions] is made up of all NUTS-2 regions in Central and Eastern Europe, except Slovenia and the most Western Czech region [Jihozapad]; and, furthermore, all the Greek and Portuguese regions; the Italian regions Calabria, Apulia, and Sicilia; the Spanish regions Galicia, Extremadura and Andalucia; Upper Austria, Lower Austria, Vienna, Burgenland, and Styria; Dresden and Berlin.

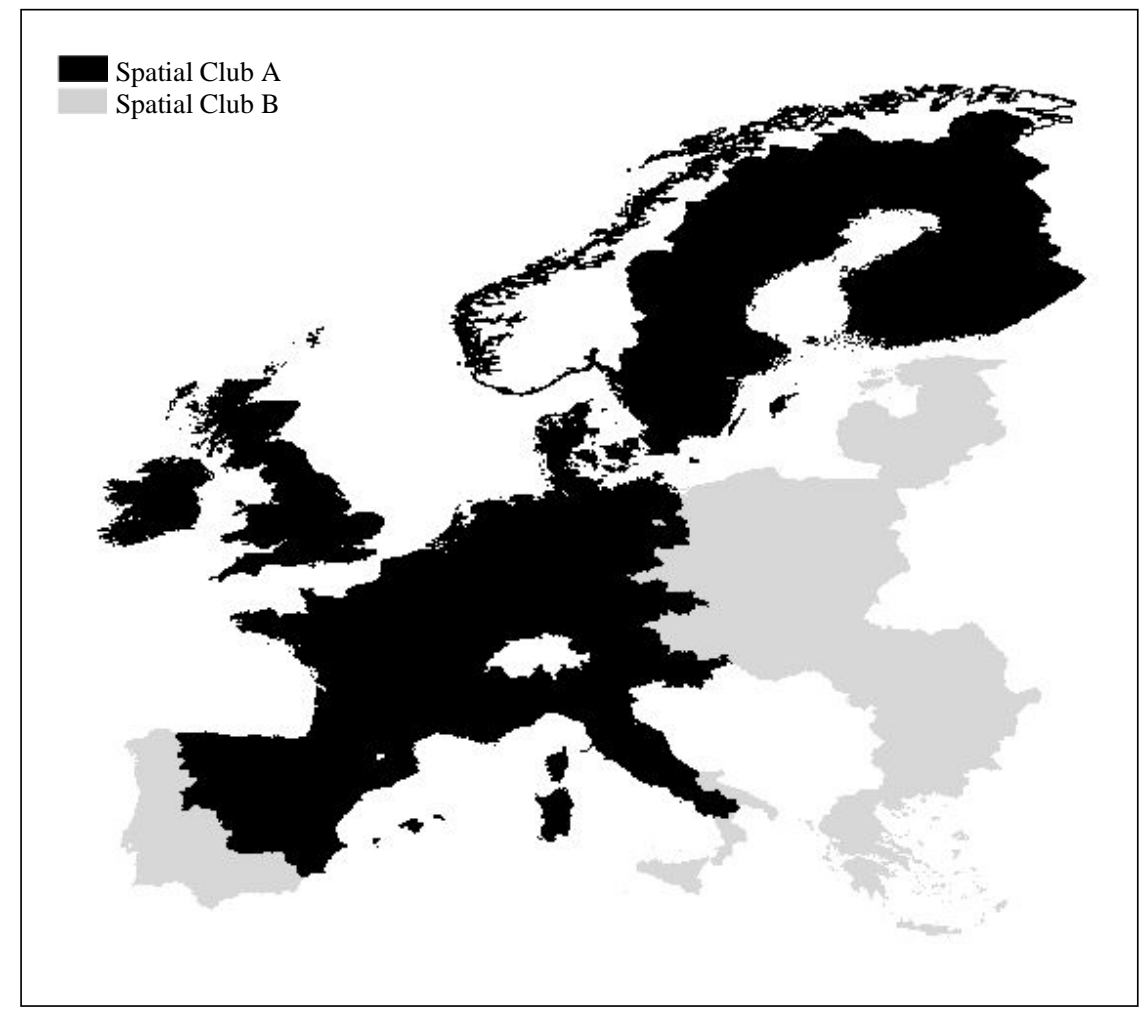

Figure 1: Two spatial regimes identified by using the Getis-Ord statistics $G_{i t}^{*}(\delta)$ [GRP per capita 1995] 


\section{Convergence Regression Results}

Table 1 present the results of the classical test methodology to convergence analysis of the 256 regional economies in Europe. The first column relates to the classical $\beta$ convergence test equation [see Equation (12)] and the second to the two-club model specification [see Equations (13) and (15)]. Recall that both test equations assume iid zero mean error terms. All estimation and specification tests were carried out with SpaceStat Software (Anselin 1999).

\section{TABLE 1 TO BE POSITIONED ABOUT HERE}

The results of both models provide much support for $ß$-convergence in Europe as the regressions yield highly significant and negative coefficients for the starting income levels. The classical convergence model estimates an annual rate of 1.9 percent of convergence. Note that this rate of convergence is slow in the sense that it would take 36.4 years (95 percent bounds: 29.9 - 46.4 years) to get half-way toward this one and common steady-state level. This result is in accordance with most studies that have yielded (un)conditional convergence rates for European regions of the order one to two percent per year [see Martin (2001) for a survey].

We should, moreover, emphasize that this result does not mean that the uneven distribution of income is shrinking ( $\sigma$-convergence). This evidence only tells that regional economies in Europe seem to approach some long-run level of income, that the growth rate falls as the regional economy approaches this long-run level and that on average poorer regional economies tend to grow faster than richer ones. This result is interesting because it suggests that regional economies which are predicted to be richer in a few decades from now on are not the same regions which are wealthy today $(\beta-$ convergence).

Recall, however, that the results of the classical convergence model are based on the assumption of a single steady-state for all regions which is largely at odds with reality. We therefore refer to a differentiation of convergence regimes. The second column in Table 1 reports the results obtained by the classical test methodology for the case of two clubs of regions as identified in the previous section. The regression yields highly significant and negative coefficients for the starting income levels ( $\hat{\beta}_{A}=-0.054$ with s.d. $=0.007$ and $\hat{\beta}_{B}=-0.021$ with s.d.=0.004) confirming the view of two-club convergence in Europe. Regions in club $A$ (starting from an on average higher level of income) saw faster GRP per capita growth over the period 1995-2000, indicating an even further income disparity between the two clubs. The estimated speed of club $A$ 
convergence is 4.8 percent per year and suggests that it will take 14.5 years (95 percent bounds: 11.7-19.2 years) for half of the distance between the initial level of income and the club $A$-specific steady-state level to vanish. In the case of club $B$ the model estimates an annual convergence rate of 2 percent. The associated half-time is 34.7 years with approximate 95 percent bounds of 25.6-54.1 years.

The bottom portion of Table 1 reports three diagnostics for the presence of spatial effects ${ }^{12}$ : a Moran's I test and two Lagrange multiplier tests. Moran's $I$ of 22.517 (second column) is very significant $(p=0.000)^{13}$. The test indicates strong evidence of positive spatial dependence and, thus, misspecification of the two-club convergence model. Unfortunately, it does not allow to discriminate between spatial lag and spatial error forms of misspecification. But - as evidenced in extensive set of Monte Carlo experiments (Anselin and Rey, 1991) - the joint use of the Lagrange multiplier tests for a spatial lag and spatial error provides good guidance. Since the (robust) Lagrange multiplier error test values exceeds the (robust) Lagrange multiplier lag test value, the two tests point to the presence of spatial error autocorrelation rather than spatial lag dependence. While there is very strong evidence for spatial dependence, the KoenkerBassett (1992) test for heteroskedasticity is not significant. Thus, we consider the spatial error specification of the two-club convergence model next.

\section{TABLE 2 TO BE POSITIONED ABOUT HERE}

Column 1 in Table 2 reports the estimation results for the spatial error specification of the two-club convergence model as defined by Equation (14) in combination with Equation (17). Note that we assume homoscedasticity of the $\mu$-error terms. Relative to the OLS regression estimates, the spatial error model achieves a better fitting as expected in terms of the log likelihood ${ }^{14}$, given the findings of the various diagnostic tests from Table 1 and the high significance of the spatial autoregressive coefficient ( $\hat{\rho}=0.908$ with $p=0.000$ ). This highlights that the classical convergence test suffers from a misspecification due to omitted spatial dependence.

12 The Jarque-Bera (19987) test that follows a $\chi^{2}$-square distribution with two degrees of freedom indicates that the non-normality requisite for the heteroskedasticity in spatial dependence test is not achieved in the current analysis.

13 Anselin and Rey (1991) show that Moran's $I$ tends to be a catchball with power against a range of alternatives including not only spatial dependence, but also non-normality and heteroskedasticity.

14 The conventional $R^{2}$-measure of fit, based on the decomposition of total sum of squared into explained and residual sum of squares is no longer appropriate. Proper measurs for goodness of fit for spatial error models are based on likelihood function. Based on the values of log likelihood the fit considerably improves with the spatial error specification of the convergence model. The improved fit is expected, since the spatial autoregression coefficient turns out to be highly significant with an asymptotic $p$-value of $p=0.000$. 
The principal finding from the club convergence point of view is that modelling spatial interactions and spillovers among regional economies drastically decreases the size of the $\beta$-convergence coefficient for club $A\left(\hat{\beta}_{A}=-0.016\right.$ with s.d.=0.006), while slightly increasing that for club $B\left(\hat{\beta}_{B}=-0.026\right.$ with s.d.=0.004). This now leads to a higher convergence speed for club $B$ than for club A which means that poorer regions are on their way of recovering towards the richer ones. The results imply an annual convergence rate of 2.4 percent for regional economies belonging to club $B$ and a convergence rate of only 1.5 percent per year for those in club $A$. Regional economies in Central and Eastern Europe only seem to take 14.5 years (95 percent bounds of 11.719.2 years) for half of the distance between the initial level of income and the clubspecific steady-state level to vanish. In the case of club $A$ the spatial error convergence model estimates an annual convergence rate of 1.5 percent. The associated half time is 45 years with approximate 95 percent bounds: 26.8-141.4 years.

The Lagrange multiplier test on residual spatial lag dependence and the Likelihood ratio test on the common factor hypothesis ${ }^{15}$ are not significant at the one percent level of significance, indicating that the spatial error model specification is appropriate. But there is one further point to consider, which suggests further elaboration of the spatial error model. The Breusch-Pagan (1979) heteroskedasticity test against the regime variable indicates some heteroskedasticity of the $\mu$-term, although no residual spatial dependence. One way to model heteroskedasticity is to assume $\sigma_{\mu_{A}}^{2} \neq \sigma_{\mu_{B}}^{2}$ (see Equation (22)). The second column in Table 2 gives the GMM estimates and summarizes the results of fitting the two-club spatial error convergence model with club-wise (groupwise) heteroskedasticity, indicating no improvement in fit as a result of modelling heteroskedasticity. The estimates of $\beta_{A}$ and $\beta_{B}$ are identical to those obtained by the spatial error model with homoskedastic error.

Classical econometric estimates (Table 1) lead us to the result that convergence speed is higher for club A (assembling the richer regions). Controlling for spatial autocorrelation in the estimates now provides us with a higher convergence speed for regions in Central and Eastern Europe in line with theoretical expectations. The extent to which the differences between the $\beta$-coefficients in the two clubs are statistically significant is indicated by the asymptotic Wald statistic constructed out of the spatial version of the Chow (1960) test (Anselin, 1990). Table 2 shows that the null hypothesis on the joint equality of coefficients $\left(\alpha_{A}=\alpha_{B}, \beta_{A}=\beta_{B}\right)$, however, cannot be rejected. Its value of 1.956 is not extreme for $\chi^{2}$-distribution with two degrees of freedom. The same indication is provided by the tests on the individual coefficients. In other words, there is no significant difference between the convergence parameters in each of the two clubs. The convergence appears to be not so different across the clubs once controlling for spatial autocorrelation.

15 See Burridge (1981) for technical details. 


\section{Concluding Remarks}

The paper has looked at the evidence for regional income convergence in the New Europe along neoclassical lines. Convergence has been identified as a property of the relation between initial income and growth over the sample period 1995-2000. Admittedly, this is a short time period, while growth and convergence are long-run processes. But the unavailability of longer homogenous time series data for the set of CEE regions prevented such an analysis at the present time. Many cross-sectional analyses of regional growth variations have detected significant evidence of (un)conditional convergence of EU-regions. But the vast majority of such studies fail to consider and model spatial dependence and heterogeneity [with very few exceptions such as Fingleton (1999)], although it is evident from the current study that such an approach may be necessary.

The focus has been on the simplest of the convergence models, the unconditional $\beta$ convergence model. In contrast to current practice we rejected the assumption of a single stable steady-state in favour of a multiple-regime [club] alternative in which different regional economies obey different linear convergence models when grouped according to initial conditions. The use of the Getis-Ord statistics produced a grouping that seems overall quite reasonable. We defined club convergence as the club-specific process by which each region belonging to a club moves from a disequilibrium position to its club-specific steady-state position. At the steady-state the growth rate is the same across the regional economies of a club.

There are four major lessons to be gained from the paper. First, there is clear evidence for unconditional $\beta$-convergence in Europe for the time period of observation. The sample of regional economies belonging to club $A$ converges in an unconditional sense at a speed of 1.5 percent per year and those belonging to club $B$ (regional economies in CEE and Southern Europe) at a speed of 2.4 percent. It is important to emphasise that a speed of 1.5 or 2.4 percent per year, even though in accordance with previous findings of convergence studies, is very small. It suggests that it will take, for example, 34.7 years in club $A$ and 14.5 years in club $B$ for half of the distance between the initial level of income and the steady-state level of the respective club to vanish. In addition, a higher convergence speed for regions in Central and Eastern Europe is evident, thus indicating a process of catching-up towards the richer Western regions.

Second and closely related, this convergence process across regional economies is an interesting finding. It suggests that regional economies in a club that are predicted to be wealthier in a few decades from now on are not the same regions in the club that are wealthy today (ß-convergence). This result does not mean, however, that the clubspecific uneven distribution of income is shrinking ( $\sigma$-convergence).

Third, the study illustrates that the classical convergence test methodology that has been the work-horse of most previous convergence studies in mainstream economics is ill- 
designed to analyse regional convergence due to several reasons. First, it cannot identify groupings of regional economies that are converging at different speeds. Second, it neglects spatial effects that represent spatial interactions and spillovers among the regional economies. The paper suggests a much richer and theoretically more satisfactory approach that incorporates spatial effects or externalities directly into the model and reflects recent developments in spatial econometrics. The two-club spatial error convergence model with club-wise heteroskedasticity appears to be the most appropriate specification in the face of the data now available.

This leads to the final point to note, namely that ignoring the presence of spatial error autocorrelation in convergence analysis carried out with cross-sectional data can lead to wrong conclusions, for example, with respect to the assessment of convergence speed. Thus, testing for the presence of spatial autocorrelation (heterogeneity) by means of appropriate diagnostics and implementing alternative specifications of the convergence test equation when needed are crucial issues in income convergence analysis.

\section{References}

Anselin, L. (1999): SpaceStat, a Software Package for the Analysis of Spatial Data, Version 1.90. BioMedware, Ann Arbor

Anselin, L. (1990): Spatial dependence and spatial structural instability in applied regression analysis, Journal of Regional Science 30(2), 185-207

Anselin, L. (1988): Spatial Econometrics: Methods and Models. Dordrecht, Kluwer

Anselin, L. and S. J. Rey (1991): Properties of tests for spatial dependence in linear regression models, Geographical Analysis 23, 112-131

Barro, R. J. (1991): Economic growth in a cross section of countries, The Quarterly Journal of Economics 106(2), 407-443

Barro, R. J. and X. Sala-i-Martin (1995): Economic Growth. New York, McGraw-Hill

Barro, R. J. and X. Sala-i-Martin (1992): Convergence, Journal of Political Economy 100(2), 223-251

Barro, R. J. and X. Sala-i-Martin (1991): Convergence across states and regions, Brookings Papers on Economic Activity 1991(1), 107-182

Baumol, W. J. (1986): Productivity growth, convergence, and welfare: What the longrun data show, The American Economic Review 76(5), 1072-1085

Bernard, A. B. and S. N. Durlauf (1996): Interpreting tests of the convergence hypothesis, Journal of Econometrics 71(1-2), 161-174

Breusch, T. and A. Pagan (1979): A simple test for heteroskedasticity and random coefficient variation, Econometrica 47, 1287-1294

Burridge, P. (1981): Testing for common factor in a spatial autoregressive model, Environment and Planning A 13, 795-800 
Button, K. J. and E. J. Pentecost (1995): Testing for convergence of the EU regional economies, Economic Inquiry 33(4), 664-671

Chow, G. (1960): Tests of equality between sets of coefficients in two linear regressions, Econometrica 28, 591-605

Dunford, M. and A. Smith (2000): Catching up or falling behind? Economic performance and regional trajectories in the 'New Europe', Economic Geography 76(2), 169-195

Durlauf, S. N. (2001): Manifesto for a growth econometrics, Journal of Econometrics $100,65-69$

Durlauf, S. N. and D. T. Quah (1999): The new empirics of economic growth, in Taylor, J. B. and M. Woodford (eds.) Handbook of Macroeconomics, Volume 1, pp. 235-308. Amsterdam, Elsevier

Durlauf S. N. and P. A. Johnson (1995): Multiple regimes and cross-country growth behaviour, Journal of Applied Econometrics 10(4), 365-384

European Commission (1999): 6th Periodic Report on the Social and Economic Situation of the Regions of the EU. Brussels, Offical Publication Office

Fingleton, B. (ed) (2003): European Regional Growth. Berlin, Heidelberg and New York, Springer

Fingleton, B. (1999): Estimates of time to economic convergence: An analysis of regions of the European Region, International Regional Science Review 22(1), 5-34

Getis, A. and J. K. Ord (1992): The analysis of spatial association by use of distance statistics, Geographical Analysis 24, 189-206

Jarque, C. M. and A. K. Bera (1987): A test for normality of observations and regression residuals, International Statistical Review 55, 163-172

Koenker, R. and G. W. Bassett (1982): Robust tests for heteroskedasticity based on regression quantiles, Econometrica 50, 43-61

Levine, R. and D. Renelt (1992): A sensitivity analysis of cross-country growth regressions, The American Economic Review 82(4), 942-963

Mankiw, N. G., Romer, D. and D. N. Weil (1992): A contribution to the empirics of economic growth, The Quarterly Journal of Economics 107(2), 407-437

Martin, R. (2001): EMU versus the regions? Regional convergence and divergence in Euroland, Journal of Economic Geography 1, 51-80

Ord, J. K. and A. Getis (1995): Local spatial autocorrelation statistics: Distributional issues and an application, Geographical Analysis 27, 286-305

Quah, D. T. (1997): Empirics for growth and distribution: Stratification, polarization, and convergence clubs, Journal of Economic Growth 2, 27-59

Quah, D. T. (1996): Empirics for economic growth and convergence, European Economic Review 40, 1353-1375

Quah, D. T. (1993): Empirical cross-section dynamics in economic growth, European Economic Review 37, 426-434

Rey, S. J. (2001): Spatial empirics for economic growth and convergence, Geographical Analysis 33(3), 195-214

Rey, S. J. and B. D. Montouri (1999): US regional income convergence: A spatial econometric perspective, Regional Studies 33(2), 143-156 
Sala-i-Martin, X. X. (1996): The classical approach to convergence analysis, The Economic Journal 106, 1019-1036

Temple, J. (1999): The new growth evidence, Journal of Economic Literature 37, 112156 


\section{APPENDIX: List of the NUTS-Level 2 Regions by Country}

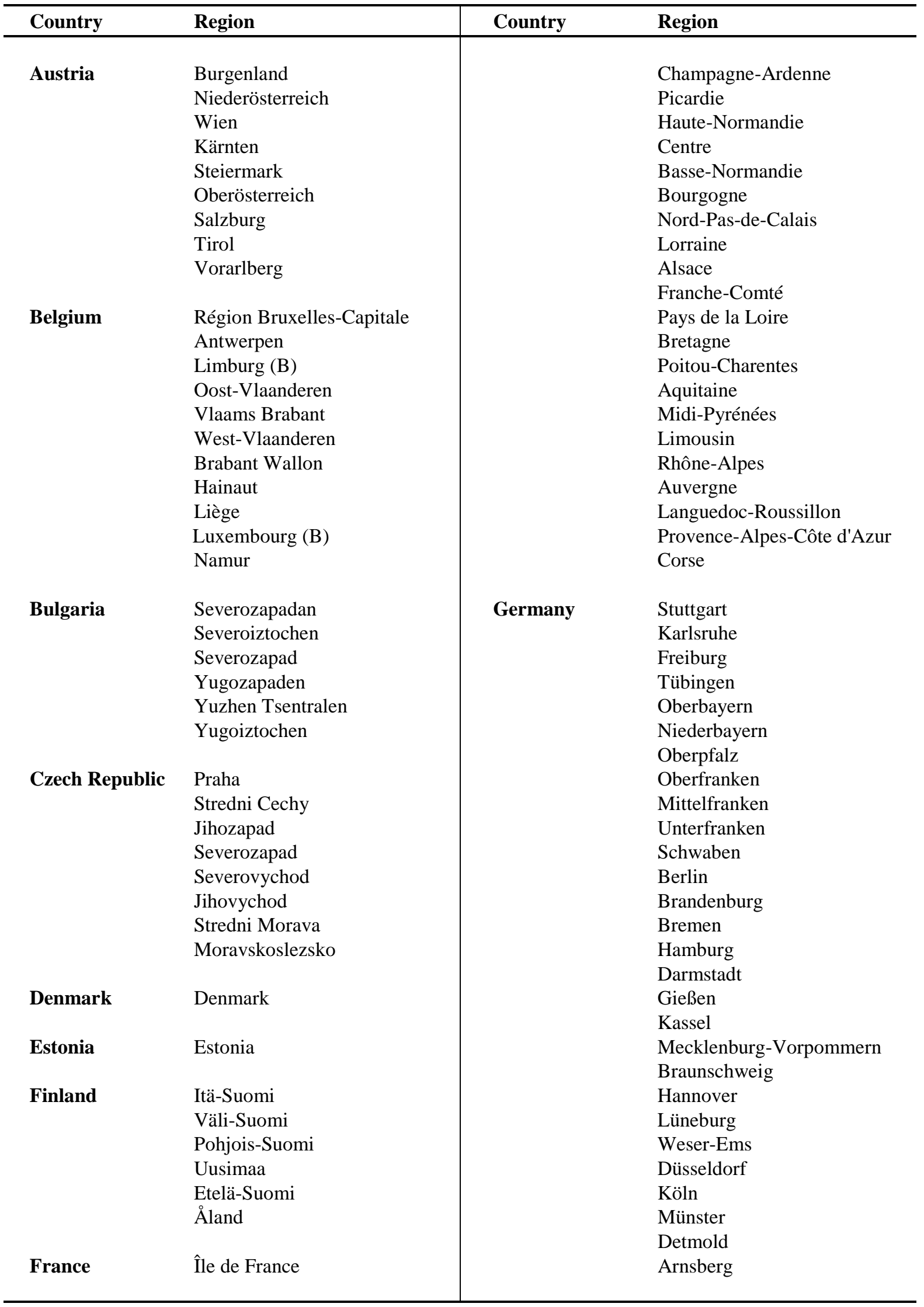


ctd.

ctd.

\begin{tabular}{|c|c|c|c|}
\hline Country & Region & Country & Region \\
\hline & $\begin{array}{l}\text { Koblenz } \\
\text { Trier } \\
\text { Rheinhessen-Pfalz } \\
\text { Saarland } \\
\text { Chemnitz } \\
\text { Dresden } \\
\text { Leipzig } \\
\text { Dessau } \\
\text { Halle } \\
\text { Magdeburg } \\
\text { Schleswig-Holstein } \\
\text { Thüringen }\end{array}$ & $\begin{array}{l}\text { Latvia } \\
\text { Lithuania } \\
\text { Luxembourg }\end{array}$ & $\begin{array}{l}\text { Campania } \\
\text { Puglia } \\
\text { Basilicata } \\
\text { Calabria } \\
\text { Sicilia } \\
\text { Sardegna } \\
\text { Latvia } \\
\text { Lithuania } \\
\text { Luxembourg }\end{array}$ \\
\hline Greece & $\begin{array}{l}\text { Anatoliki Makedonia, Thraki } \\
\text { Kentriki Makedonia } \\
\text { Dytiki Makedonia } \\
\text { Thessalia } \\
\text { Ipeiros } \\
\text { Ionia Nisia } \\
\text { Dytiki Ellada } \\
\text { Sterea Ellada } \\
\text { Peloponnisos } \\
\text { Attiki } \\
\text { Voreio Aigaio } \\
\text { Notio Aigaio } \\
\text { Kriti }\end{array}$ & The Netherlands & $\begin{array}{l}\text { Groningen } \\
\text { Friesland } \\
\text { Drenthe } \\
\text { Overijssel } \\
\text { Gelderland } \\
\text { Flevoland } \\
\text { Utrecht } \\
\text { Noord-Holland } \\
\text { Zuid-Holland } \\
\text { Zeeland } \\
\text { Noord-Brabant } \\
\text { Limburg (NL) }\end{array}$ \\
\hline Hungary & $\begin{array}{l}\text { Közép-Magyarország } \\
\text { Közép-Dunántúl } \\
\text { Nyugat-Dunántúl } \\
\text { Dél-Dunántúl } \\
\text { Észak-Magyarország } \\
\text { Észak-Alföld } \\
\text { Dél-Alföld }\end{array}$ & Poland & $\begin{array}{l}\text { Dolnoslaskie } \\
\text { Kujawsko-Pomorskie } \\
\text { Lubelskie } \\
\text { Lubuskie } \\
\text { Lódzkie } \\
\text { Malopolskie } \\
\text { Mazowieckie } \\
\text { Opolskie }\end{array}$ \\
\hline Ireland & $\begin{array}{l}\text { Border, Midland and Western } \\
\text { Southern and Eastern }\end{array}$ & & $\begin{array}{l}\text { Podkarpackie } \\
\text { Podlaskie } \\
\text { Pomorskie } \\
\text { Slaskie }\end{array}$ \\
\hline Italy & $\begin{array}{l}\text { Piemonte } \\
\text { Valle d'Aosta } \\
\text { Liguria } \\
\text { Lombardia } \\
\text { Trentino-Alto Adige }\end{array}$ & & $\begin{array}{l}\text { Swietokrzyskie } \\
\text { Warminsko-Mazurskie } \\
\text { Wielkopolskie } \\
\text { Zachodniopomorskie }\end{array}$ \\
\hline & $\begin{array}{l}\text { Veneto } \\
\text { Friuli-Venezia Giulia } \\
\text { Emilia-Romagna } \\
\text { Toscana } \\
\text { Umbria } \\
\text { Marche }\end{array}$ & Portugal & $\begin{array}{l}\text { Norte } \\
\text { Centro (P) } \\
\text { Lisboa e Vale do Tejo } \\
\text { Alentejo } \\
\text { Algarve }\end{array}$ \\
\hline & $\begin{array}{l}\text { Lazio } \\
\text { Abruzzo } \\
\text { Molise }\end{array}$ & Romania & $\begin{array}{l}\text { Nord-Est } \\
\text { Sud-Est } \\
\text { Sud }\end{array}$ \\
\hline
\end{tabular}


ctd.

ctd.

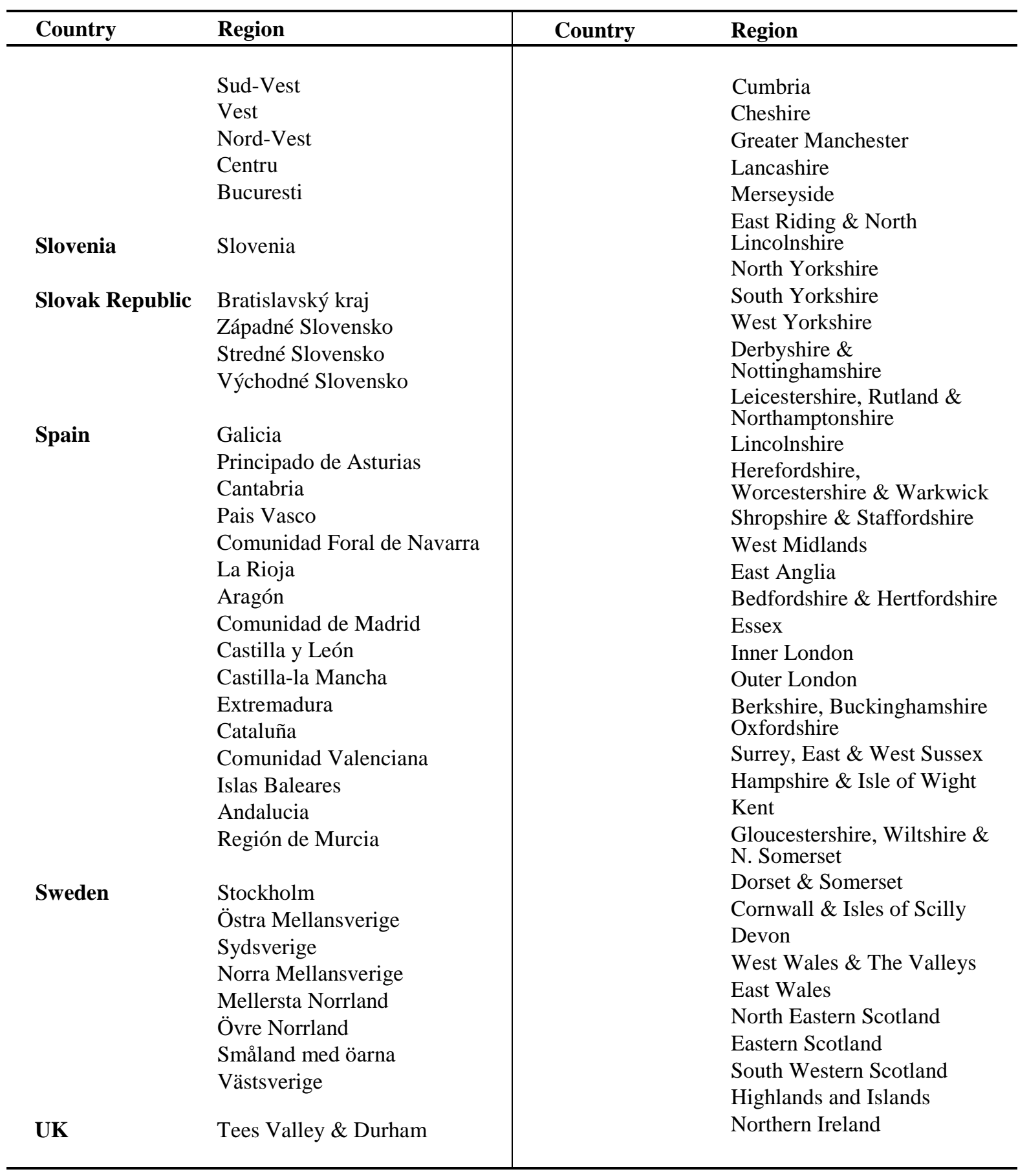


Table 1: Convergence Regression Results for the 256 European Regions, 1995-2000: The Classical Test Methodology

\begin{tabular}{ccc}
\hline & $\begin{array}{c}\text { The Classical } \\
\text { Convergence Model } \\
\text { [OLS] }\end{array}$ & $\begin{array}{c}\text { The Classical Two-Club } \\
\text { Convergence Model } \\
\text { [OLS] }\end{array}$ \\
\hline $\begin{array}{c}\text { Parameter Estimates } \\
(p \text {-values in brackets) } \\
\text { Intercept } \\
\text { Club } A\end{array}$ & & \\
Club $B$ & $0.248(0.000)$ & \\
Beta & & $0.580(0.000)$ \\
Club $A$ & $-0.020(0.000)$ & $0.250(0.000)$ \\
Club $B$ & & $-0.054(0.000)$ \\
\hline
\end{tabular}

The Time to Convergence

Annual Convergence Rate

(in percent)

Club $A$

1.9

Club $B$

4.8

2.0

Half-Distance to the Steady-State

(in years, 95\% bounds in brackets)

Club $A$

$36.4(29.9-46.4)$

Club $B$

$14.5(11.7-19.2)$

$34.7(25.6-54.1)$

\begin{tabular}{lrc}
\hline Performance Measures & & \\
$R^{2}$ & 0.239 & 0.307 \\
Log likelihood & 513.949 & \\
Sigma sq. & 0.00106 & 0.00098 \\
\hline
\end{tabular}

Diagnostic Tests

( $p$-values in brackets)

Normality

Jarque-Bera

Heteroskedasticity

Koenker-Bassett

Structural Instability for the

Two Regimes

Chow-Wald

513.949

0.00098

Stability of Individual

Coefficients

Constant

Beta

$27.197(0.000) \quad 22.274(0.000)$

$1.928(0.165) \quad 0.717(0.397)$

Spatial Error Dependency

Moran's $I$

$26.590(0.000) \quad 22.592(0.000)$

Robust Lagrange Multiplier $\quad 145.639(0.000) \quad 45.588(0.000)$

Spatial Lag Dependency

Robust Lagrange Multiplier

$1.536(0.216)$

$24.226(0.000)$

Notes: Rho $[\rho]$ is the parameter of the autoregressive error process, Beta $[\beta]$ the convergence coefficient, $R^{2}$ squared correlation [ML] or $R^{2}$ adjusted [OLS, GMM], Sigma sq. the error variance. The speed of convergence per year is computed as $\hat{\beta}^{*}=-\ln (1-\tau \hat{\beta}) / \tau$ with s.e. $\left(\hat{\beta}^{*}\right)=$ s.e. $(\hat{\beta}) / \exp \left(-\hat{\beta}^{*} \tau\right)$, where $\tau$ is the length of time. The half-distance to the steady-state is computed as $\ln (2) / \hat{\beta}^{*}$ with the approximate confidence interval defined as $\ln (2) /\left(\hat{\beta}^{*} \pm 2\right.$ s.e. $\left.\left(\hat{\beta}^{*}\right)\right)$. 
Table 2: Convergence Regression Results for the 256 European Regions, 1995-2000: Spatial Error Specifications of the Two-Club $\beta$-Convergence Model

\begin{tabular}{|c|c|c|}
\hline & $\begin{array}{c}\text { The Two-Club Spatia } \\
\text { The Homoskedastic } \\
\text { Case } \\
\text { [ML] } \\
\end{array}$ & $\begin{array}{c}\text { ror Convergence Model } \\
\text { The Heteroskedastic } \\
\text { Case } \\
\text { [GMM] } \\
\end{array}$ \\
\hline \multicolumn{3}{|l|}{$\begin{array}{l}\text { Parameter Estimates } \\
\text { ( } p \text {-values in brackets) }\end{array}$} \\
\hline $\begin{array}{r}\text { Intercept } \\
\text { Club } A \\
\text { Club } B\end{array}$ & $\begin{array}{l}0.204(0.001) \\
0.297(0.000)\end{array}$ & $\begin{array}{l}0.206(0.000) \\
0.296(0.000)\end{array}$ \\
\hline $\begin{array}{l}\text { Beta } \\
\text { Club } A \\
\text { Club } B \\
\text { Rho } \\
\end{array}$ & $\begin{array}{r}-0.016(0.004) \\
-0.026(0.000) \\
0.908(0.000) \\
\end{array}$ & $\begin{array}{r}-0.016(0.001) \\
-0.026(0.000) \\
0.904(0.000) \\
\end{array}$ \\
\hline \multicolumn{3}{|l|}{ The Time to Convergence } \\
\hline \multicolumn{3}{|c|}{$\begin{array}{l}\text { Annual Convergence Rate } \\
\text { (in percent) }\end{array}$} \\
\hline $\begin{array}{l}\text { Half-Distance to the } \\
\text { (in years, } 95 \% \text { bounds } \\
\text { Club } A \\
\text { Club } B\end{array}$ & $\begin{array}{r}45.0(26.8-141.4) \\
14.5(11.7-19.2)\end{array}$ & $\begin{array}{r}45.0(26.8-141.4) \\
14.5(11.7-19.2)\end{array}$ \\
\hline $\begin{array}{c}\text { Performance Measures } \\
R^{2} \\
\text { Log likelihood } \\
\text { Sigma sq. } \\
\end{array}$ & $\begin{array}{r}0.353 \\
634.179 \\
0.00037 \\
\end{array}$ & 0.345 \\
\hline \multicolumn{2}{|l|}{$\begin{array}{l}\text { Diagnostic Tests } \\
\text { ( } p \text {-values in brackets) }\end{array}$} & \\
\hline $\begin{array}{l}\text { Spatial Error Depend } \\
\text { Likelihood Ratio }\end{array}$ & $216.754(0.000)$ & \\
\hline $\begin{array}{l}\text { Spatial Lag Depender } \\
\text { Lagrange Multipliel }\end{array}$ & $6.159(0.013)$ & \\
\hline \multicolumn{2}{|c|}{ Common Factor hypothesis } & \\
\hline $\begin{array}{l}\text { Structural Instability } \\
\text { Two Regimes } \\
\text { Chow-Wald }\end{array}$ & $1.927(0.382)$ & $1.941(0.379)$ \\
\hline \multicolumn{3}{|l|}{$\begin{array}{l}\text { Stability of Individual } \\
\text { Coefficients }\end{array}$} \\
\hline Constant & $1.758(0.185)$ & $1.804(0.179)$ \\
\hline Beta & $1.889(0.169)$ & $1.832(0.176)$ \\
\hline
\end{tabular}

Notes: see Table 1. 